DE

M E D I C I N A

T R O P I C A L

$\mathrm{DE}$

SÃO PAULO

JOURNAL OF THE SÃO PAULO INSTITUTE OF TROPICAL MEDICINE

(1) Universidade Federal de Uberlândia, Faculdade de Medicina, Departamento de Clínica Médica, Uberlândia, Minas Gerais, Brazil

(2) Universidade Federal de Uberlândia, Escola Técnica de Saúde, Uberlândia, Minas Gerais, Brazil

(3) Universidade Federal de Uberlândia, Hospital de Clínicas de Uberlândia, Uberlândia, Minas Gerais, Brazil

(4) Universidade Federal de Uberlândia, Laboratório Clínico, Uberlândia, Minas Gerais, Brazil

(5) Universidade Federal de Uberlândia, Faculdade de Matemática, Uberlândia, Minas Gerais, Brazil

(6) Universidade Federal de Uberlândia, Instituto de Ciências Biomédicas, Uberlândia, Minas Gerais, Brazil

Correspondence to: Paula Augusta Dias Fogaça de Aguiar.

Universidade Federal de Uberlandia, Faculdade de Medicina, Departamento de Clínica Médica, Av. Pará, 1720, CEP 38408 100, Uberlandia, MG, Brazil. Tel: +5534 3218-2698

E-mail: paulinhapatoclinica@bol.com.br

Received: 11 February 2016

Accepted: 13 February 2017

\section{The epidemiology of cryptococcosis and the characterization of Cryptococcus neoformans isolated in a Brazilian University Hospital}

\author{
Paula Augusta Dias Fogaça de Aguiar ${ }^{1}$, Reginaldo dos Santos Pedroso², \\ Aércio Sebastião Borges ${ }^{3}$, Tomaz de Aquino Moreira ${ }^{4}$, Lúcio Borges de \\ Araújo $^{5}$, Denise Von Dolinger de Brito Röder 6
}

\section{ABSTRACT}

Cryptococcosis, a systemic disease caused by the fungus Cryptococcus neoformans/ Cryptococcus gattii is more severe in immunocompromised individuals. This study aimed to analyze the epidemiology of the disease, the molecular characteristics and the antifungal susceptibility of $C$. neoformans isolated from patients treated in a Brazilian university hospital. This retrospective study was conducted in the Clinical Hospital, Federal University of Uberlândia, and evaluated cases of cryptococcosis and strains of C. neoformans isolated from 2004 to 2013 . We evaluated 41 patients, $85 \%$ of whom were diagnosed with AIDS. The fungus was isolated from the cerebrospinal fluid (CSF) of 21 patients (51\%); $19.5 \%$ had fungemia and in $24 \%$ the agent was isolated from the CSF and blood, concurrently. Meningoencephalitis was the most frequent $(75 \%)$ manifestation of infection. Despite adequate treatment, the mortality of the disease was $58.5 \%$. Most isolates $(97.5 \%)$ presented the VNI genotype (serotype A, var. grubii) and one isolate was genotyped as C. gattii (VGI); all the isolates were determined as mating type MAT $\alpha$ and showed susceptibility to the tested antifungals (fluconazole, voriconazole, amphotericin B and 5-flucytosine). Although AIDS detection rates remain stable, opportunistic infections such as cryptococcosis remain as major causes of morbidity and mortality in these patients

KEYWORDS: Cryptococcus neoformans. Cryptococcosis. Molecular typing. Antifungal susceptibility testing.

\section{INTRODUCTION}

Fungi of the complex Cryptococcus neoformans/Cryptococcus gattii are encapsulated, cosmopolitan yeasts, and are able to infect and cause disease in many hosts, including man ${ }^{1}$. Cryptococcosis, an illness caused by these microorganisms, is a systemic disease that may be subacute or chronic and potentially fatal, and primarily affects the meninges. Its occurrence was rare before the acquired immunodeficiency syndrome (AIDS) epidemic, and was usually associated with patients presenting low cellular immunity ${ }^{2}$. As a global causative agent, $C$. neoformans is estimated to cause more than one million new cases of cryptococcosis a year with about 625,000 deaths ${ }^{3}$. C. neoformans is usually associated with immunocompromised individuals (AIDS patients, neutropenic individuals and those receiving prolonged therapy with corticosteroids); $C$. gattii is more often associated with immunocompetent patients ${ }^{4}$.

Cryptococcus neoformans has serotypes A, D and AD; in contrast, C. gattii that has serotypes $\mathrm{B}$ and $\mathrm{C}$. The former species also presents two varieties related 
to serotypes var. grubii (serotype A) and var. neoformans (serotype D) $)^{5,6}$. Serotype A predominates in clinical and environmental isolates in most areas, except in Northern European countries, where serotype D accounts for $50 \%$ of the isolates ${ }^{7}$. Serotype AD was isolated from the environment and in patients in North America and Europe ${ }^{8}$. Until recently, the accepted idea was that $C$. gattii was restricted to tropical and subtropical areas. However, an outbreak in Vancouver Island, Canada, reported in 2002, changed assumptions about the pattern of distribution of this species ${ }^{9}$.

The treatment of cryptococcosis has been the subject of numerous studies. Currently, only three classes of antifungal drugs have been considered for this purpose: the polyenes (amphotericin B), the azoles (ketoconazole, itraconazole, fluconazole and voriconazole) and a pyrimidine-derived drug (5- flucytosine) ${ }^{10}$. The latter is not available in Brazil. However, some of the drugs administered to treat fungal infections have high failure rates, and the emergence of fungal intrinsic resistance is a growing problem ${ }^{11,12}$. Regarding the treatment of HIV-positive patients with fungal infections of the mucous membranes, in the period preceding the introduction of antiretroviral therapy, the repeated and prolonged use of azoles favored the acquisition of drug resistance in several fungal pathogens, including C. neoformans ${ }^{13}$.

The aims of this study were to evaluate the epidemiological profile of patients who had developed cryptococcosis and to determine their susceptibility to antifungal drugs, and also to explore the molecular characteristics of $C$. neoformans isolated from patients treated at the Clinical Hospital of the Federal University of Uberlândia (HCU) from 2004 to 2013.

\section{MATERIALS AND METHODS}

In this retrospective study, 41 strains of Cryptococcus that had been previously identified as $C$. neoformans were included. They were isolated from patients treated at the Clinical Hospital of Uberlândia from 2004 to 2013. These strains were stored in the Clinical Laboratory of that institution from the time of diagnosis until the time of this study. Uberlândia is a city located in the western region of the State of Minas Gerais, Brazil. The strains were isolated from various clinical samples (cerebrospinal fluid [CSF], blood, skin lesion secretions and bronchoalveolar lavage).

The study was carried out after been approved by the Ethics Committee of the Federal University of Uberlândia (UFU), under number 357.803, in 08.13.2013. In the Microbiology Laboratory of the HCU, the phenotypic identification of Cryptococcus spp. is routinely carried out using classical phenotypic tests such as the hydrolysis of urea and canavanine glycine bromothymol blue agar (CGB). To ensure the viability of the strains, they were maintained on Sabouraud Dextrose agar (SDA) at room temperature with quarterly subcultures. These stored strains were evaluated in this study.

To evaluate the epidemiological profile of patients who had developed cryptococcosis, we studied patient charts. They were analyzed to gather data on demographics (gender, age, base disease, immunosuppression causes, CD4 lymphocyte count, treatment and outcome of the disease) and the primary isolation site of Cryptococcus sp.

Antifungal susceptibility was identified using the VITEK $^{\circledR} 2$ system (Biomérieux), according to the manufacturer's instructions. The inoculum suspension was prepared from cultures in SDA, incubated for 48 hours at $35^{\circ} \mathrm{C}$, with turbidity adjusted to the standard number 2 of McFarland. This suspension was transferred to cassettes of a susceptibility test card system (AST-YS01, Ref. 22108). The cassettes were inserted in the system and the minimal inhibitory concentration (MIC) levels were determined in an automated equipment. The results were expressed in $\mu \mathrm{g} / \mathrm{mL}$. The concentrations of drugs in the cassettes ranged from 1 to $32 \mu \mathrm{g} / \mathrm{mL}$ for amphotericin B, 1 to $16 \mu \mathrm{g} / \mathrm{mL}$ for fluconazole, from 4 to $64 \mu \mathrm{g} / \mathrm{mL}$ for 5 -flucytosine (5FC) and from 0.5 to $8 \mu \mathrm{g} / \mathrm{mL}$ for voriconazole. Candida albicans ATCC $^{\circledR} 90028$ was used as the control. Although clinical breakpoints for imidazole derivatives, including fluconazole, have not yet been defined in the literature, the strains with a MIC $<8 \mu \mathrm{g} / \mathrm{mL}$ were considered susceptible to fluconazole ${ }^{14}$.

Although one of the aims of this study was to explore the molecular characteristics of Cryptococcus neoformans, phenotypic tests were repeated before performing the molecular characterization. These tests were conducted after recovery of the isolates through three serial subcultures, incubated for 72 hours. The phenotypic identification of the strains was performed in the last subculture using the same tests described previously (classical phenotypic tests).

Molecular tests were carried out after the extraction of genomic DNA, according to Bolano et al. ${ }^{15}$, with the modifications advised by Pedroso et al. ${ }^{16}$. Mating types and molecular types were determined. To establish the mating type, two pairs of primers were used as described by Chatuverdi et al. ${ }^{17}$ : MAT $\alpha$ [MAT $\alpha \mathrm{F}$ (5' -CTTCACTGCCATCTTCACCA-3'); MAT $\alpha \mathrm{R}$ (5'-GACACAAAG GGTCATGCCA-3')], and MATa [MATaF (5'-CGCCTTCACTGCTACCTTCT-3'); and MAT $\alpha$ R (5'-AACGCAAGAGTAAGTCGGGC-3')]. Amplification reactions were performed in a final volume of $25 \mu \mathrm{L}$, each tube containing $25 \mathrm{ng}$ of genomic DNA, 
enzyme buffer 1X (Uniscience, São Paulo, Brazil), 1.5 $\mathrm{mM}$ magnesium chloride (Uniscience, São Paulo, Brazil), $0.2 \mathrm{mM}$ of each dNTP (Ludwig Biotec, RS, Brazil), 20 picomoles of each primer, and $1 \mathrm{U}$ Taq polymerase (Uniscience, SP, Brazil). The amplification conditions were: initial denaturation at $94{ }^{\circ} \mathrm{C}$ for 4 minutes, 34 cycles at 94 ${ }^{\circ} \mathrm{C}$ for 1 minute, $63^{\circ} \mathrm{C}$ and $60^{\circ} \mathrm{C}$ for 1 minute, respectively, for MAT $\alpha$ or MATa, extension at $72{ }^{\circ} \mathrm{C}$ for 1 minute, followed by a final extension at $72{ }^{\circ} \mathrm{C}$ for 10 minutes. Reactions were kept at $4{ }^{\circ} \mathrm{C}$. The amplification products generated from the PCR reactions were subjected to agarose gel electrophoresis in 1\% TBE (Tris, Boric acid, EDTA) $0.5 \mathrm{X}$ plus $5 \mu \mathrm{L} / \mathrm{mL}$ fluorescent dye Easy View (Easy Path, $\mathrm{SP}$, Brazil), using $5 \mu \mathrm{L}$ of the amplified product run at 75 $\mathrm{V}$ for 90 minutes. Then, the gel was visualized using an ultraviolet transilluminator (L-Pix HE, Loccus do Brasil, SP, Brazil) and photographed using the Lab-Image ID photo documentation system (Loccus do Brasil, SP, Brazil). The presence of amplified fragments of $101 \mathrm{bp}$ and $117 \mathrm{bp}$ was considered positive for $\alpha$ and $a$ types, respectively. For the results analysis, strains of $C$. neoformans INCQS 40123 (ATCC $^{\circledR}$ 28957) and C. neoformans ATCC $^{\circledR} 28958$ were used as controls for $\alpha$ and a types, respectively.

Amplification reactions for URA-5 gene were performed as described in the literature ${ }^{18,19}$, with a final volume of $25 \mu \mathrm{L}$ containing $50 \mathrm{ng}$ of genomic DNA, 1X enzyme buffer (Uniscience, São Paulo, Brazil), 1.5 mM magnesium chloride (Uniscience, SP, Brazil), $0.2 \mathrm{mM}$ of each dNTP (Ludwig Biotec, RS, Brazil), 20 picomoles of each primer URA-5 (5'-ATGTCCTCCCAAGCCCTCG ACTCCG-3') and SJ01 (5'-TTAAGACCTCTGAACACCGTACTC-3'); and $1 \mathrm{U}$ of
Taq polymerase (Uniscience, SP, Brazil). Reaction conditions were: initial denaturation at $94{ }^{\circ} \mathrm{C}$ for 4 minutes, 34 cycles at $94{ }^{\circ} \mathrm{C}$ for 1 minute, annealing at $57^{\circ} \mathrm{C}$ for 1 minute, extension at $72^{\circ} \mathrm{C}$ for 1 minute, followed by a final extension at $72{ }^{\circ} \mathrm{C}$ for 10 minutes. Samples were kept at $4{ }^{\circ} \mathrm{C}$. Thirty microliters of the reaction amplicon were doubly digested with Sau96I (10 U/ $\mu \mathrm{L})$ and HhaI $(20 \mathrm{U} / \mu \mathrm{L})$ (New England Biolabs, Uniscience, SP, Brazil), and incubated at $37^{\circ} \mathrm{C}$ for 3 hours. The fragments were separated on $3 \%$ agarose gel at $100 \mathrm{~V}$ for 5 hours $^{18}$. We used the controls VNI (serotype A), VNII (serotype A), VNII (serotype AD), VNIV (serotype D) and VGI-VGIV (C. gattii) for the interpretation and analysis of results (Figure 1).

Data were described (in terms of frequencies and percentages) by means of an entry table for each variable, as well as by using dual input tables. Associations were evaluated using the likelihood ratio test ${ }^{20}$. The level of significance was set at $5 \%(\mathrm{p}<0.05)$. The statistical procedures were performed using the SPSS software v. 20 (IBM, NY, USA).

\section{RESULTS}

Of the 41 patients evaluated, there were seven women $(17 \%)$ and 34 men (83\%). Most patients were aged from 20 to 40 years; most women were in the 20-30 years old group (Table 1). There was no statistically significant difference between men and women in relation to age $(\mathrm{p}>0.05)$.

Table 2 shows the distribution of patients according to the underlying disease. Most of them (35 [90\%]) were immunocompromised. In 35 patients (85\%) the underlying

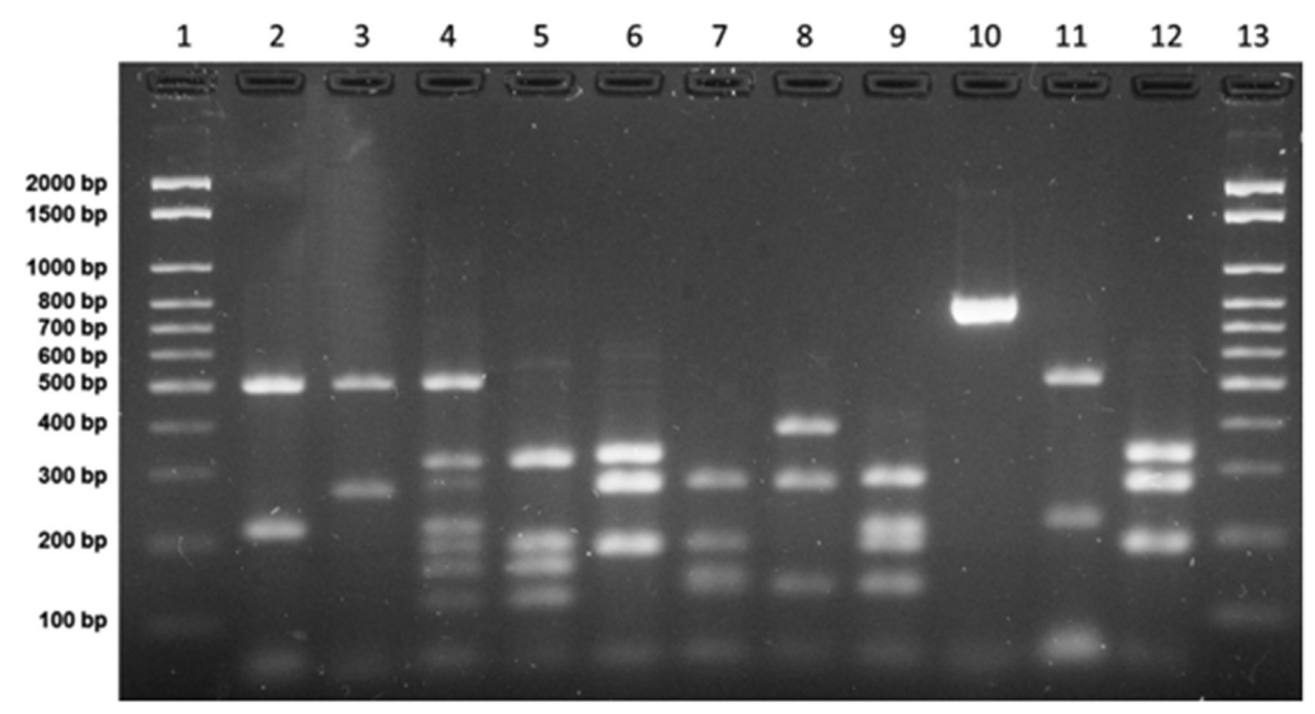

Figure 1 - RFLP profiles (URA5 genes) from C. neoformans/C. gattii control strains. Columns 1 and 13: molecular markers (100 bp); columns 2 to 5: genotypes VNI, VNII, VNIII and VNIV, respectively; columns 6 to 9: genotypes VGI, VGII, VGIII and VGIV, respectively; column 10 is URA5 gene amplified product; columns 11 and 12 are clinical isolates Cryptococcus neoformans VNI and Cryptococcus gattii VGI, respectively. 
Table 1 - Frequency of cryptococcosis according to the age and the gender of patients treated at the HCU, 2004-2013

\begin{tabular}{lcccc}
\hline \multirow{2}{*}{$\begin{array}{l}\text { AGE } \\
\text { (years) }\end{array}$} & \multicolumn{3}{c}{ MALE } & \multicolumn{2}{c}{ FEMALE } \\
\cline { 2 - 5 } & $\mathrm{n}$ & $\%$ & $\mathrm{n}$ & $\%$ \\
\hline $20-30$ & 10 & 29.4 & 3 & 42.8 \\
$31-40$ & 14 & 41.2 & 1 & 14.3 \\
$41-50$ & 6 & 17.6 & 1 & 14.3 \\
$51-60$ & 1 & 2.9 & 0 & 0.0 \\
$61-69$ & 1 & 2.9 & 2 & 28.6 \\
$\geq 70$ & 2 & 6.0 & 0 & 0.0 \\
\hline Total & 34 & 82.9 & 7 & 17.1 \\
\hline
\end{tabular}

Table 2 - Distribution of underlying diseases associated with cryptococcosis in patients treated at the HCU, 2004-2013

\begin{tabular}{lcc}
\hline \multirow{2}{*}{ Base Disease } & \multicolumn{2}{c}{ Frequency } \\
\cline { 2 - 3 } & $\mathrm{n}$ & $\%$ \\
\hline AIDS & 35 & 85.0 \\
Chronic alcohol abuse & 1 & 2,5 \\
Leprosy+Rheumatoid arthritis & 1 & 2.5 \\
Hypertension + gout & 1 & 2.5 \\
Psoriatic arthritis & 1 & 2.5 \\
Not reported & 2 & 5.0 \\
\hline Total & 41 & $100 \%$ \\
\hline
\end{tabular}

disease was AIDS. Other diseases were chronic alcohol abuse, rheumatoid arthritis, leprosy, psoriatic arthritis, hypertension and gout; patients with these diseases were chronic corticosteroids or other immunosuppressive drugs users. In two patients, there was no evidence of immune impairment in their medical records.

Among AIDS patients, 17 had a CD4 lymphocyte count $<200$ cells $/ \mathrm{mm}^{3}$, with values ranging from 5-196 cells $/ \mathrm{mm}^{3}$. In other patients, this exam was not performed during the hospitalization period.
Cryptococcal meningoencephalitis was the predominant clinical form of cryptococcosis: in $21(51 \%)$ the fungus was isolated from the CSF only, eight (19\%) from the blood culture only, 10 (24\%) from the CSF and blood culture, one (3\%) from the secretions of skin lesions, and one (3\%) from the bronchoalveolar lavage (BAL) (Table 3).

Thirty-five patients $(85 \%)$ received antifungal therapy, and all of them were treated with amphotericin B; fluconazole was used in 25 patients $(71 \%)$ during the consolidation phase. The remaining patients (15\%) died before treatment.

The lethality of cryptococcosis was estimated at $58.5 \%$. Among the patients who died, most had isolated fungemia or fungemia associated with meningoencephalitis $(p=0.001)$. Among the 35 patients with AIDS, 21 (60\%) died; among the four patients with other causes of immunosuppression (all male), one (25\%) died; however, there was no statistical difference $(p=0.133)$ between the evolution of disease in the AIDS patients compared to those with other causes of immunosuppression (Table 4). There was no statistical difference regarding the clinical outcome of men and women $(p=0.935)$.

Table 5 shows some characteristics of cryptococcosis regarding the clinical outcome of patients.

All the isolates were susceptible to the tested antifungal agents, showing a MIC $<8 \mu \mathrm{g} / \mathrm{mL}$ for fluconazole.

Most isolates (97.6\%) were genotyped as C. neoformans var. grubii (serotype A, VNI genotype). However, one isolate $(2.4 \%)$ previously phenotyped as $C$. neoformans (positive urea hydrolysis test and negative CGB test) was genotyped as $C$. gattii (VGI genotype) (Figure 2). All the strains presented the MAT $\alpha$ mating type.

\section{DISCUSSION}

This study has evaluated cases of cryptococcosis occurring at the Uberlândia Clinical Hospital from 2004 to 2013. Most patients (68\%) were aged between 20-40 years (both genders) and had AIDS. The Brazilian Health

Table 3 - Distribution of clinical forms of cryptococcosis according to the isolation site from patients treated at the HCU, 2004-2013

\begin{tabular}{lccc}
\hline \multirow{2}{*}{ Clinical Form } & \multicolumn{2}{c}{ Frequency } & Isolation site \\
\cline { 2 - 4 } & $\mathrm{N}$ & $\%$ & CSF \\
Meningoencephalitis & 21 & 51.2 & Skin lesion secretion \\
Cutaneous cryptococcosis & 1 & 2.5 & Blood \\
Fungaemia & 8 & 19.5 & CSF+blood \\
Meningoencephalitis + fungaemia & 10 & 24.3 & 2.5 \\
Pulmonary cryptococcosis & 1 & 100 & BAL \\
\hline Total & 41 &
\end{tabular}


Table 4 - Clinical outcome of patients with cryptococcosis treated at the HCU from 2004 to 2013

\begin{tabular}{|c|c|c|c|c|c|c|c|c|c|c|c|c|c|c|}
\hline \multirow{4}{*}{$\begin{array}{l}\text { Clinical } \\
\text { outcome }\end{array}$} & \multicolumn{12}{|c|}{ Patients } & \multirow{2}{*}{\multicolumn{2}{|c|}{ TOTAL }} \\
\hline & \multicolumn{6}{|c|}{ MALE } & \multicolumn{6}{|c|}{ FEMALE } & & \\
\hline & \multicolumn{2}{|c|}{ NR } & \multicolumn{2}{|c|}{$\mathrm{HIV+}$} & \multicolumn{2}{|c|}{ HIV- } & \multicolumn{2}{|c|}{ NR } & \multicolumn{2}{|c|}{$\mathrm{HIV+}$} & \multicolumn{2}{|c|}{ HIV- } & & \\
\hline & $\mathrm{n}$ & $\%$ & $\mathrm{n}$ & $\%$ & $\mathrm{n}$ & $\%$ & $\mathrm{n}$ & $\%$ & $\mathrm{n}$ & $\%$ & $\mathrm{n}$ & $\%$ & $\mathrm{n}$ & $\%$ \\
\hline Survived & 0 & 0.0 & 11 & 32.0 & 3 & 9.0 & 0 & 0.0 & 3 & 43.0 & 0 & 0 & 17 & 41.5 \\
\hline Died & 1 & 3.0 & 18 & 53.0 & 1 & 3.0 & 1 & 14.0 & 3 & 43.0 & 0 & 0 & 24 & 58.5 \\
\hline TOTAL & 1 & 3.0 & 29 & 85.0 & 4 & 12.0 & 1 & 14.0 & 6 & 86.0 & 0 & 0 & 51 & 100.0 \\
\hline
\end{tabular}

NR: Not reported; HIV: Human Immunodeficiency Virus

Table 5 - Comparison of variables according to the clinical outcome of patients with cryptococcosis treated at the HCU from 2004 to 2013

\begin{tabular}{|c|c|c|c|c|c|c|}
\hline \multirow{3}{*}{ Variables } & \multicolumn{4}{|c|}{ Clinical evolution } & \multirow{3}{*}{$\begin{array}{c}\text { Total (41) } \\
\mathrm{n}\end{array}$} & \multirow{3}{*}{$p$ value } \\
\hline & \multicolumn{2}{|c|}{ SURVIVED (17) } & \multicolumn{2}{|c|}{ DIED (24) } & & \\
\hline & $\mathrm{N}$ & $\%$ & $\mathrm{n}$ & $\%$ & & \\
\hline Male & 14 & 41.2 & 20 & 51.8 & 34 & 0.935 \\
\hline AIDS & 14 & 40.0 & 21 & 60.0 & 35 & 0.133 \\
\hline Meningoencephalitis & 15 & 48.3 & 16 & 51.7 & 31 & 0.025 \\
\hline Fungemia & 0 & 0.0 & 8 & 100.0 & 8 & 0.001 \\
\hline Pulmonary form & 1 & 100.0 & 0.0 & 0.0 & 1 & 0.180 \\
\hline Treatment & 17 & 48.6 & 18 & 51.4 & 35 & 0.008 \\
\hline Fluconazol & 15 & 60.0 & 10 & 40.0 & 25 & 0.028 \\
\hline Amphotericin B & 15 & 42.8 & 20 & 57.2 & 35 & 0.082 \\
\hline
\end{tabular}

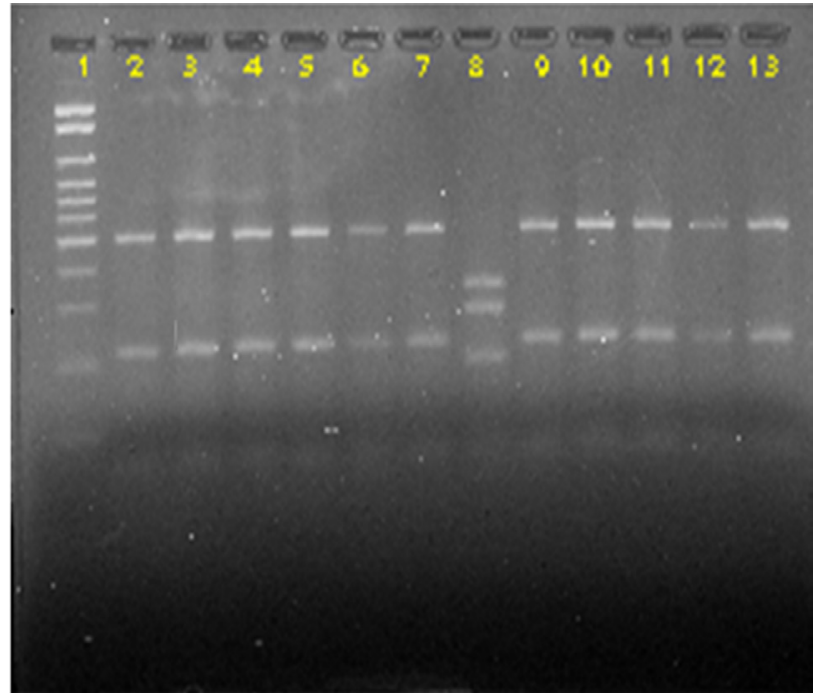

Figure 2 - RFLP profile of the URA5 genes from Cryptococcus sp obtained by double-digestion with Hhal and Sau96I. Column 1: Molecular maker (100 bp). Columns 2 to 7: isolated 2, 4, 5, 6, 7 and 8 (VNI), respectively; column 8: isolated 12 (VGI); Columns 9 to 13: isolates 13, 18, 22, 24 and 25 (VNI), respectively.

Ministry $^{21}$ data indicates the highest prevalence of AIDS in patients between 25 and 39 years in both genders. Brazilian studies show the highest prevalence of cryptococcosis in this age group, with slight variations concerning the age groups 20-30 years and 31-40 years ${ }^{22,23}$. Mezzari et al. ${ }^{24}$ studied the epidemiology of cryptococcosis in a public hospital in Rio Grande do Sul, Brazil and reported that most patients were aged 30-39 years. Patients in this age group were born and raised in the period coinciding with the emergence and spread of HIV, which was accompanied by changes in sexual behavior, including increased number of partners, thereby contributing to the spread of HIV and of opportunistic infections such as cryptococcosis.

In Brazil, cryptococcosis occurs as the first manifestation of an opportunistic disease in over $4 \%$ of AIDS patients, and is as one of its defining illnesses ${ }^{10}$. The present study contained more men $(83 \%)$ than women. According to the AIDS Epidemiological Bulletin ${ }^{21}$ data, there was an increase of $4.3 \%$ in the detection rates of the disease in men during the study period, while there was a significant decrease $(14 \%)$ among women. Moreira et $a l .{ }^{25}$ studied the epidemiology of cryptococcosis in the HCU and also reported a higher prevalence of the disease in males, with a similar percentage in the present study. According to Carvour et al. ${ }^{26}$, despite the predominance in males, women with meningoencephalitis have a worse prognosis than men, with lower survival rates. In this study there was no 
significant difference between men and women in relation to prognosis and survival.

All 39 patients (95\%) with a documented immune status were immunocompromised and most were AIDS patients (35 [90\%]). C. neoformans infections in immunocompromised hosts are widely described in the literature ${ }^{27,28,29}$. Among the AIDS patients, only 17 (48.5\%) had CD4/CD8 T lymphocyte counts recorded in their medical notes, and most had been previously diagnosed with AIDS. These patients had less than 200 cells $/ \mathrm{mm}^{3}$ and, in 15 of them $(88 \%)$, the count was less than 100 cells $/ \mathrm{mm}^{3}$. In a cohort study of 700 patients, Jarvis et al..$^{30}$ observed an increased risk of meningoencephalitis when patients had CD4 counts below 100 cells $/ \mathrm{mm}^{3}$. The $\mathrm{WHO}^{31}$ recommends screening with the Cryptococcus antigen test (CRAG) in AIDS patients who have CD 4 counts below 100 cells $/ \mathrm{mm}^{3}$. In those who have tested positive, treatment with fluconazole should be promptly initiated in order to prevent cryptococcosis. These recommendations, however, are not based on clinical evidence ${ }^{32}$.

According to the Brazilian Consensus on Cryptococcosis ${ }^{10}$, in over $80 \%$ of the cryptococcosis cases, the predominant clinical form is meningoencephalitis. The fungus was detected in the CSF of 31 patients (75\%) in the present study; many studies have shown meningoencephalitis to be the predominant clinical form ${ }^{3,23,25,28,33,34,35,36}$. In eight patients (19\%), the fungus was found only in the blood. Studies have shown that fungemia by Cryptococcus spp. may be present in $47-71 \%$ of AIDS patients. However, this percentage is $27 \%$ among those not infected by $\mathrm{HIV}^{27}$. In this study, of the eight patients with isolated fungemia, six (75\%) had AIDS. The other two patients had no medical report regarding their immune status. All the patients (10 [24\%]) in whom the fungus was present in the CSF and blood, as detected by culture, had AIDS.

Thirty-five patients received specific treatment for cryptococcosis with drugs available in Brazil (amphotericin $\mathrm{B}$ and fluconazole) according to the management guidelines of the disease ${ }^{10,37,38}$. Amphotericin B was started for all the patients; however, 10 (28.5\%) died in the early induction phase before fluconazole could be started (during the consolidation phase). Six patients (14\%) who had fungemia received no treatment because, we believe, they presented a serious initial clinical form of disease with hemodynamic instability. In these patients, the diagnosis of cryptococcosis was made only after the fungus was isolated in their blood cultures, and this occurred post mortem. Of these untreated patients, four (66\%) had AIDS and the immune status of the other two was unknown.

In the present study, the overall mortality associated with cryptococcosis was high and demonstrates the severity of the disease, despite the use of specific treatment. In Brazil, according to the literature, mortality rates range from $26 \%$ to $70 \%{ }^{23,24,25,39}$; in the present study the mortality rate was $58.5 \%$. The factors that influence this outcome include the virulence of $C$. neoformans, the slow response to treatment with amphotericin $\mathrm{B}$, the advanced stage of the patients immunosuppression (particularly those with AIDS), and the superimposition of opportunistic infections, for example, neurotoxoplasmosis, pneumocystosis, that have worsened clinical conditions.

In Brazil, studies of the in vitro susceptibility of Cryptococcus spp. have shown that most isolates are susceptible to polyene antifungals, 5-flucytosine and azoles $^{10}$. However, the in vivo resistance of $C$. neoformans to imidazole derivatives (especially to fluconazole) is well documented in the literature, especially in patients with AIDS who have meningoencephalitis and who use this drug for prolonged periods ${ }^{10,11,40}$. Silva et al..$^{41}$ suggested that treatment failure can occur due to the development of resistance to amphotericin B. Nevertheless, the present study found that all the isolates were susceptible in vitro to the tested drugs. The reference methodology indicated by $\mathrm{CLSI}^{42}$ to perform antifungal susceptibility tests to C. neoformans used the microdilution broth method, but Tweari et al. $^{43}$ found that the technique used by Vitek ${ }^{\circledR} 2$ shows good accuracy for antifungal susceptibility testing, particularly to fluconazole and amphotericin, presenting an agreement level with the reference methodology of $80 \%$ and $90 \%$, respectively.

C. neoformans var. grubii has been isolated from various environmental sources and from clinical samples. In Brazil, this species is prevalent in the Southeastern and Southern States $^{2}$. In the present study, all the identified isolates as C. neoformans comprised var. grubii (serotype A, VNI genotype). This confirms the prevailing distribution of this species in the State of Minas Gerais ${ }^{18,22}$. Some studies indicate that over $80 \%$ of cases of cryptococcosis are caused by var. grubii, mostly in AIDS patients ${ }^{44,45}$.

All the isolates considered in this study were mating type MAT $\alpha$, a finding consistent with the literature ${ }^{46}$. DesnosOllivier et al. ${ }^{28}$ studied 400 samples of $C$. neoformans (serotype A-244, serotype D-76 and serotype AD-70) isolated in France and found no MAT a sample in serotype A (all of them were MAT $\alpha$ ); only 13 serotype D samples were MATa.

This study demonstrates the importance of using molecular methods in the correct identification of clinical isolates. One of the isolates previously identified as $C$. neoformans presented a VGI genotype, showing that it was actually the species $C$. gattii. This isolate gave a negative CGB test result. This is an interesting finding because 
the results from epidemiological studies based only on classical techniques can diverge from those based on the most accurate methods. In general, clinical laboratories use the CGB test to distinguish between the two major species, C. neoformans and C. gattii. This test has been routinely used in laboratories since its proposal in $1982^{47}$. Despite being a simple biochemical test that is relatively rapid (requiring 10 days of incubation), although expensive, the CGB may result in reactions that are difficult to interpret, generating both, false positive and false negative results ${ }^{48}$. The correlation between the molecular identification and the CGB test varies according to the study, from $95.4 \%$ to $100 \%{ }^{49,50}$. Some studies ${ }^{45,51,52}$ suggest that the phenotypic identification of Cryptococcus spp. must be confirmed by molecular techniques such as RFLP-PCR, which for C. neoformans enables serotype and molecular typing at the same time. Although the use of molecular methods to identify the species of Cryptococcus may still be infrequent in routine microbiology laboratories, these have become efficient alternatives, being more sensitive, specific, timely, and being less influenced by external factors than the traditional phenotypic methods ${ }^{18,19,51,53}$.

In summary, in this study, cryptococcosis was most prevalent in male patients with AIDS and, despite the institution of appropriate drug therapy, most patients died. C. neoformans var. grubii (VNI genotype) was the main etiological agent, and all of the isolates showed in vitro susceptibility to the tested antifungal agents. It is worth noting the growing importance of molecular methods for the proper identification of Cryptococcus species, since traditional phenotypic methods may fail.

\section{CONTRIBUTIONS}

All the authors participated in drafting and reviewing the paper and made relevant contributions. They have all given their final approval to, and agreed to be accountable for, all the aspects of the study.

\section{ACKNOWLEDGMENTS}

We thank the clinical analysis laboratories of $\mathrm{HCU}$, and the technical team from the Technical School of Health (ESTES), Federal University of Uberlândia (UFU), for the physical space and supplies to accomplish this work. Érika Bezerra de Melo Riceto and Ralciane Paula Menezes for their technical support in some experiments. Mario Leon Silva Vergara, Délio José Mora Amador Júnior and Leonardo Eurípedes de Andrade e Silva, from Triângulo Mineiro Federal University (UFTM), for providing the control isolates VNI and VGI; and Luciana Trilles, from
Oswaldo Cruz Foundation (FIOCRUZ), for providing the molecular types reference strains.

\section{CONFLICT OF INTERESTS}

None.

\section{REFERENCES}

1. Lacaz CS, Porto E, Martins JE, Heins-Vaccari EM, Melo NT. Criptococose. In: Lacaz CS, editor. Tratado de micologia médica. $9^{\text {a }}$ ed. São Paulo: Sarvier; 2002.

2. Pappalardo MC, Melhem MS. Cryptococcosis: a review of the Brazilian experience for the disease. Rev Inst Med Trop Sao Paulo. 2003;45:299-305.

3. Park BJ, Wannemuehler KA, Marston BJ, Govender N, Pappas PG, Chiller TM. Estimation of the current global burden of cryptococcal meningitis among persons living with HIV/AIDS. AIDS. 2009;23:525-30.

4. Bicanic T, Harrison TS. Cryptococcal meningitis. Br Med Bull. 2005;72:99-118.

5. Kwon-Chung KJ, Varma A. Do major species concepts support one, two or more species within Cryptococcus neoformans? FEMS Yeast Res. 2006;6:574-87.

6. Del Poeta M, Casadevall A. Ten challenges on Cryptococcus and cryptococcosis. Mycopathologia. 2012;173:303-10.

7. Casadevall A, Perfect JR. Cryptococcus neoformans. Washington: ASM Press; 1998.

8. Lengeler KB, Cox GM, Heitman J. Serotype AD strains of Cryptococcus neoformans are diploid or aneuploid and are heterozygous at the mating-type locus. Infect Immun. 2001;69:115-22.

9. Kidd SE, Hagen F, Tscharke RL, Huynh M, Bartlett KH, Fyfe M, et al. A rare genotype of Cryptococcus gattii caused the cryptococcosis outbreak on Vancouver Island (British Columbia, Canada). Proc Natl Acad Sci U S A. 2004;101:17258-63.

10. Consenso em criptococose - 2008. Rev Soc Bras Med Trop. 2008;41:524-44.

11. Cheong JW, McCormack J. Fluconazole resistance in cryptococcal disease: emerging or intrinsic? Med Mycol. 2013;51:261-9.

12. Smith KD, Achan B, Hullsiek KH, McDonald TR, Okagaki LH, Alhadab AA, et al. Increased antifungal drug resistance in clinical isolates of Cryptococcus neoformans in Uganda. Antimicrob Agents Chemother. 2015;59:7197-204.

13. Magalhães YC, Bomfim MR, Melônio LC, Ribeiro PC, Cosme LM, Rhoden CR, et al. Clinical significance of the isolation of Candida species from hospitalized patients. Braz J Microbiol. 2015;46:117-23.

14. Espinel-Ingroff A, Aller AI, Canton E, Castaño-Olivares LR, Chowdhary A, Cordoba S, et al. Cryptococcus neoformans- 
Cryptococcus gattii species complex: an international study of wild-type susceptibility endpoint distributions and epidemiological cutoff values for fluconazole, itraconazole, posaconazole, and voriconazole. Antimicrob Agents Chemother. 2012;56:5898-906.

15. Bolano A, Stinchi S, Preziosi R, Bistonin F, Allegrucci M, Baldelli F, et al. Rapid methods to extract DNA and RNA from Cryptococcus neoformans. FEMS Yeast Res. 2001;1:221-4.

16. Pedroso RS, Lavrador MA, Ferreira JC, Candido, RC, Maffei CM. Cryptococcus neoformans var. grubii - Pathogenicity of environmental isolates correlated to virulence factors, susceptibility to fluconazole and molecular profile. Mem Inst Oswaldo Cruz. 2010;105:993-1000.

17. Chatuverdi S, Rodeghier B, Fan J, Mc Clelland CM, Wickles BL, Chatuverdi V. Direct PCR of Cryptococcus neoformans MAT and MAT a pheromones to determine mating type, ploidy, and variety: a tool for epidemiological and molecular pathogenesis studies. J Clin Microbiol. 2000;38:2007-9.

18. Meyer W, Castañeda A, Jackson S, Huynh M, Castañeda E. Molecular typing of Iberoamerican Cryptococcus neoformans isolates. Emerg Infect Dis. 2003;9:189-95.

19. Mora DJ, Pedrosa AL, Rodrigues V, Leite Maffei CM, Trilles L, Dos Santos Lazéra M, et al. Genotype and mating type distribution within clinical Cryptococcus neoformans and Cryptococcus gattii isolates from patients with cryptococcal meningitis in Uberaba, Minas Gerais, Brazil. Med Mycol. 2010;48:561-9.

20. Agresti A. An introduction to categorical data analysis. $2^{\text {nd }}$ ed. New York: John Wiley \& Sons; 2007.

21. Brasil. Ministério da Saúde. Boletim epidemiológico HIV-AIDS. Brasília: Ministério da Saúde; 2014.

22. Leal AL, Faganello J, Fuentefria AM, Boldo JT, Bassanesi MC, Vainstein MH. Epidemiological profile of cryptococcal meningitis patients in Rio Grande do Sul, Brazil. Mycopathologia. 2008;166:71-5.

23. Mora DJ, da Cunha Colombo ER, Ferreira-Paim K, AndradeSilva LE, Nascentes GA, Silva-Vergara ML. Clinical, epidemiological and outcome features of patients with cryptococcosis in Uberaba, Minas Gerais, Brazil. Mycopathologia. 2012;173:321-7.

24. Mezzari A, Wliebbeling AM, Freitas GS, May GG, Albé GC, Filik HP, et al. Criptococose em um hospital público de Porto Alegre: dados epidemiológicos. J Infect Control. 2013;2:135-9.

25. Moreira TA, Ferreira MS, Ribas MR, Borges AS. Criptococose: estudo clínico-epidemiológico, laboratorial e das variedades do fungo em 96 pacientes. Rev Soc Bras Med Trop. 2006;39:255-8.

26. Carvour ML, Harms JP, Lynch CF, Mayer RR, Meier JL, Liu D, et al. Differential survival for men and women with HIV/AIDSrelated neurologic diagnoses. PLoS One. 2015;10:e0123119.

27. Antinori S. New insights into HIV/AIDS-associated cryptococcosis. ISRN AIDS. 2013;2013:471363.
28. Desnos-Ollivier M, Patel S, Raoux-Barbot D, Heitman J, Francoise D. Cryptococcosis serotypes impact outcome and provide evidence of Cryptococcus neoformans speciation. MBio. 2015;6:e00311.

29. Idnurm A, Lin X. Rising to the challenge of multiple Cryptococcus species and the diseases they cause. Fungal Genet Biol. 2015;78:1-6.

30. Jarvis JN, Meintjes G, Williams A, Brown Y, Crede T, Harrison TS. Adult meningitis in a setting of high HIV and TB prevalence: findings from 4961 suspected cases. BMC Infect Dis. 2010;10:67.

31. World Health Organization. Rapid advice: diagnosis, prevention and management of cryptococcal disease in HIV-infected adults, adolescents and children. Geneva: WHO; 2011.

32. Masur H. HIV-related opportunistic infections are still relevant in 2015. Top Antivir Med. 2015;23:116-9.

33. Lindenberg AS, Chang MR, Paniago AM, Lazéra MS, Moncada PM, Bonfim GF, et al. Clinical and epidemiological features of 123 cases of cryptococcosis in Mato Grosso do Sul, Brazil. Rev Inst Med Trop Sao Paulo. 2008;50:75-8.

34. Pappas PG. Cryptococcosis in the developing world: an elephant in the parlor. Clin Infect Dis. 2010;50:345-6.

35. Pappas PG. Cryptococcal infections in non-HIV-infected patients. Trans Am Clin Climatol Assoc. 2014;123:61-79.

36. Sloan DJ, Parris V. Cryptococcal meningitis: epidemiology and therapeutic options. Clin Epidemiol. 2014;6:169-82.

37. Perfect JR, Dismukes WE, Dromer F, Goldman DL, Graybill JR, Hamill RJ, et al. Clinical practice guidelines for the management of cryptococcal disease: 2010 update by the Infectious Diseases Society of America. Clin Infect Dis. 2010;50:291-322.

38. Perfect JR, Bicanic T. Cryptococcosis diagnosis and treatment: what do we know now. Fungal Genet Biol. 2015;78:49-54.

39. Souza LK, Costa CR, Fernandes OF, Abrão FY, Silva TC, Treméa $\mathrm{CM}$, et al. Clinical and microbiological features of cryptococcal meningitis. Rev Soc Bras Med Trop. 2013;46:343-7.

40. Friese G, Discher T, Füssle R, Schmalreck A, Lohmever J. Development of azole resistance during fluconazole maintenance therapy for AIDS-associated cryptococcal disease. AIDS. 2001;15:2344-5.

41. Silva PR, Rabelo RA, Terra AP, Teixeira DN. Suscetibilidade a antifúngicos de variedades de Cryptococcus neoformans isoladas de pacientes em hospital universitário. Rev Soc Bras Med Trop. 2008;41:158-62.

42. Clinical and Laboratory Standards Institute. Reference method for broth dilution antifungal susceptibility testing of yeasts: third informational supplement. Wayne: Clinical and Laboratory Standards Institute; 2008.

43. Tewari A, Behera B, Mathur P, Xess I. Comparative analysis of the Vitek 2 Antifungal Susceptibility System and E-test with the CLSI M27-A3 broth microdilution method for susceptibility 
testing of Indian clinical isolates of Cryptococcus neoformans. Mycopathologia. 2012;173:427-33.

44. Perfect JR, Casadevall A. Cryptococcosis. Infect Dis Clin North Am. 2002;16:837-74.

45. MeyerW, Trilles L. Genotyping of the Cryptococcus neoformans/C. gattii species complex. Australian Biochemist. 2010;41:12-5.

46. Kwon-Chung KJ, Edman JC, Wickes BL. Genetic association of mating types and virulence in Cryptococcus neoformans. Infect Immun. 1992;60:602-5.

47. Kwon-Chung KJ, Bennett JE. Medical mycology. Philadelphia: Lea \& Febiger; 1992.

48. Khan ZU, Al-Anezi AA, Chandy R, Xu J. Disseminated cryptococcosis in an AIDS patient caused by a canavanineresistant strain of Cryptococcus neoformans var. grubii. J Med Microbiol. 2003;52:271-5.

49. Klein KR, Hall L, Deml SM, Rysavy JM, Wohlfiel SL, Wengenack NL. Identification of Cryptococcus gattii by use of L-canavanine glycine bromothymol blue medium and DNA sequencing. J Clin Microbiol. 2009;47:3669-72.
50. Gomes, FS, Santo EP, Sarmento DN, Silva, SH. Quimiotipagem e caracterização fenotípica de Cryptococcus. Rev Pan-Amaz Saude. 2010;1:43-9.

51. Trilles L, Lazéra MS, Wanke B, Oliveira RV, Barbosa GG, Nishikawa MM, et al. Regional pattern of the molecular type of Cryptococcus neoformans and Cryptococcus gattii in Brazil. Mem Inst Oswaldo Cruz. 2008;103:455-62.

52. Trilles L, Wang B, Firacative C, Lazéra MS, Wanke B, Meyer W. Identification of the major molecular types of Cryptococcus neoformans and $\mathrm{C}$. gattii by hyperbranched rolling circle amplification. PLoS One. 2014;9:e94648.

53. Hagen F, Khayhan K, Theelen B, Kolecka A, Polacheck I, Sionov $\mathrm{E}$, et al. Recognition of seven species in the Cryptococcus gattii/Cryptococcus neoformans species complex. Fungal Genet Biol. 2015;78:16-48. 